\title{
GLOBALIZACIÓN E IDENTIDAD COLECTIVA EN LA MODERNIDAD AVANZADA
}

\author{
Torclito Pérez de Guzmán \\ Universidad de Sevilla
}

\section{UN ENFOQUE RELACIONAL}

Los mecanismos de identidad y exclusión constituyen una parte inevitable de la fábrica de . $r$ sociedad y, por tanto, se encuentran en todos los agrupamientos humanos. Como nos enseñó Yary Douglas (1966), cabe calificar a las personas de animales clasificadores con más propiedad - ue de animales racionales. La clasificación es una herramienta imprescindible en la confección je nuestros mapas mentales, en nuestra construcción social de la realidad. Y toda clasificación - $u$ ue afecte al agente clasificador se resuelve en una antinomia nosotros/ellos que es el caldo de :ultivo de la identidad y la exclusión.

En una palabra. puede considerarse a las exclusiones como una constante en la historia de .4 humanidad. Pero eso no quiere decir que en cada época. en cada contex to cultural, no adquiera asgos diferenciales tanto cuantitativos como cualitativos. De ahí que no sea ocioso preguntarnos - Láles son las características que singularizan estos fenómenos en el seno de las sociedades :mmersas en la modernidad avanzada.

Si la hipercomplejidad es nota definitoria de los sistemas sociales, tal complejidad ha sscalado un peldaño más en los tiempos actuales con el aumento exponencial de la información Visponible y con la interconexión mundial de estructuras sociales antes segmentadas. Por ello ¿uestro análisis no debe recurrir al clásico examen de cadenas causales lineales (un procedimiento - onfortable por lo familiar que nos resulta, pero en exceso simple); es casi imprescindible efectuar .na ruptura epistemológica y emplear una aproximación basada en la lógica relacional, más idónea :nte lo enmarañado del tema que nos ocupa. En consecuencia. el esquema analítico que sirve de nilo conductor a este discurso no es un hilo' en términos estrictos, sino una red de fenómenos mutuamente conectados por relaciones formando causaciones circulares y probablemente - usceptibles de engendrar 'cualidades emergentes' en cualquiera de los puntos del circuito donde, como dicen los cibernéticos, anide una transición de fase, una bifurcación imprevisible de la linámica del sistema.

El esquema propuesto parte de la hipótesis de que los dos grandes factores diferenciales a la identidad y la exclusión en la modernidad aranzada son la globalización y los nuevos nodos de heterogeneidad social. alimentados respectivamente por el debilitamiento de la ideologia 
del Estado-nación y por una reestructuración de la jerarquía de valores que definen la moral individual y la ética colectiva. Ambos factores, que se refuerzan mutuamente, están también ligados al antes mencionado incremento de la información disponible y al desarrollo de sistemas de clasificación social crecientemente sofisticados; y todo ello, en definitiva, prefigura los modos de identificación y exclusión que dan una facies específica a los tiempos que corren. Esta exposición se centrará en analizar someramente los referidos factores y sus interconexiones, cuya expresión gráfica podría plasmarse de la siguiente manera:

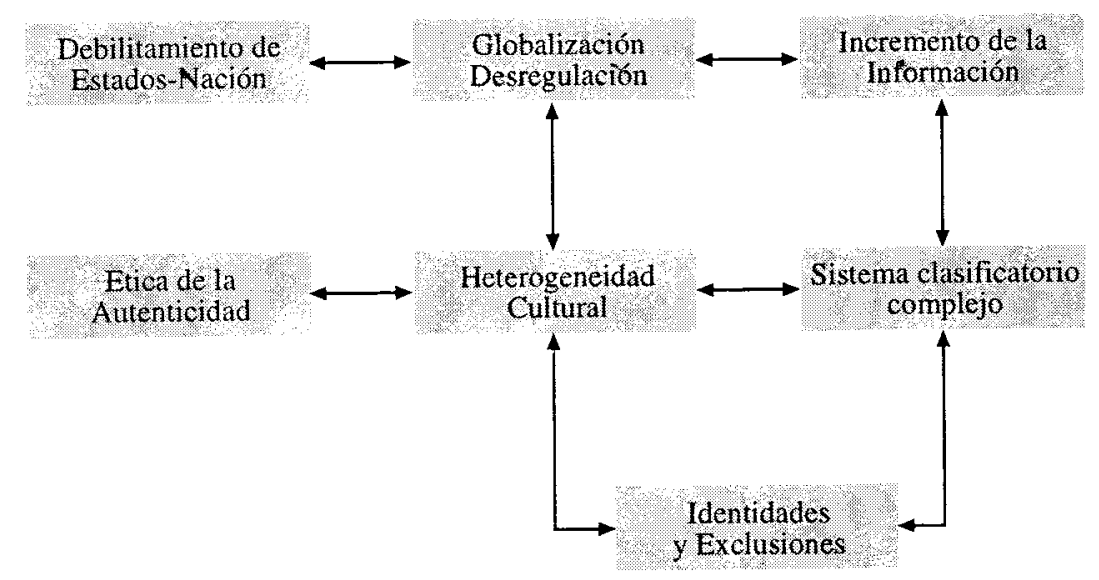

Cuando se trata de ahondar en el tema de la exclusión resulta difícil abstraerse del sufrimiento, las privaciones, las indignidades y hasta la sangre que conlleva ese fenómeno. Pero, como nos enseña el Eclesiastés (3,1) todas las cosas tienen su tiempo; igual que en la vida hay un tiempo de esparcir piedras y un tiempo de recogerlas, en la ciencia hay un tiempo de reflexión y otro de acción. Los últimos desarrollos de la filosofía de la ciencia han puesto de manifiesto cuán ingenua era la postura de Max Weber (1980) cuando, en contra de los pronunciamientos de Marx, predicaba la separación de la actividad científica y la política. El análisis y la praxis deben estar coordinados aunque sólo sea porque, según nos aleccionan las teorías de la complejidad y el caos, es más fácil producir el futuro que predecirlo (Pérez de Guzmán, 1997:764). Eso no obsta para que investigación y acción precisen una disposición de ánimo y unas reglas diferentes, de modo que conviene realizarlas cada una en su tiempo para que ambas -sin perjuicio de que se iefuerzan mutuamente- alcancen su máxima virtualidad.

Ahora es el momento de la reflexión. Una reflexión que, contemplada sin perspectiva, puede parecer descarnada y desencarnada, incluso cínica y falta de piedad. Pero ese es el precio a pagar si queremos construir un instrumento apropiado para la acción posterior.

\section{BASES CONTEXTUALES DE LA OTREDAD}

Ya se dijo que van a tomarse como tales dos de los rasgos más sobresalientes de la modernidad avanzada: el incremento de la heterogeneidad intra-comunal y el proceso de globalización: dos fenómenos no antagónicos sino complementarios.

En cualquier caso, es preciso introducir aquí una perspectiva temporal de los acontecimientos. Hablamos de modernidad avanzada como si fuese un rasgo que domina al Primer mundo, pero la realidad es que su tiempo todavía no ha llegado a la sazón. Partes importantes de 
muestras culturas siguen constituyendo relictos del pasado. mientras que otras representan meras emillas del futuro que colonizan el presente. En pocas palabras: la modemidad avanzada ha arragado desigualmente entre nosotros. de modo que vivimos en lo que Riggs denomina una sociedad prismática' cuajada de aparentes contradicciones. de anacronismos en potencia. Hay ples que tomar en sus justos términos esta exposición. que incidirá precisamente en los aspectos k la modernidad avanzada que más visiblemente están impregnando nuestras vidas.

\section{1. La naturaleza de la globalización}

Este factor se nos presenta como una ruptura de la legitimidad exclusiva de lo que hemos iamado relaciones internacionales. cuyo referente es, como indica la propia expresión, la dimensión nacional.

Para una cabal aprehensión del asunto conviene explicitar que en el párrafo anterior se han equiparado. como es el uso. la dimensión nacional con el Estado. Y sin embargo importa muy mucho dejar sentado que se trata de dos conceptos diferentes. No es usual percatarse de que el nacionalismo es un dios Jano, un fenómeno con dos caras y una sola idea raiz. Están los Estadosnación, reconocidos como tales en el contexto internacional: y están los nacionalismos 'periféricos' también llamados 'étnicos'). que se autoconsideran 'naciones sin Estado' y cuya meta típica -en uasiones matizada u oculta- es conseguir la condición de la que carecen.

La base común de ambos modelos de nacionalismo es la creencia nacida con la Ilustración de que el Estado-nación constituye la 'unidad política natural' (Gellner. 1983:409). Por lo tanto. el mundo tiene que estar repartido entre Estados. a modo de piezas de un rompecabezas que ocupe toda su superficie. Sólo la Antáltida. territorio sin posibilidades de mantener un pueblo. se ha escapado por ahora de esa férrea generalización. Con esa excepción. no hay un palmo del planeta que no esté incluido en algún Estado: de ahí que Birch (1989:3) llegue a afirmar que el nacionalismo es la ideología más exitosa en la historia de la humanidad. mucho más ye el liberalismo, el marxismo o cualquiera de las religiones en su mayor momento de esplendor. Pero can impresionante triunfo es raramente percibido: debido precisamente a su éxito, ese invento de hace dos o tres siglos ha penetrado en nuestras vidas hasta el extremo de convertirse en el cntorno familiar que está ahí. que ha estado 'siempre' y que. por ende. no hace notar su presencia.

Pero ahondemos algo más en sus caracteres. El primer punto a resaltar es que no se trata meramente de una ideología de puertas adentro, como los bien conocidos etnocentrismos. Además de eso. proporciona un modo de hablar del mundo compartido por todos. En el ámbito político ictual cada 'nosotros' necesita confirmarse no tanto frente a los 'otros' como por el hecho de ser un 'otro' de nuestros 'otros'. reconocido en tanto que entidad parigual. Por eso la categoría 'nacional' ¿ una etiqueta a la vez concreta y abstracta (Billig. 1995:64): se puede discutir si tal nación existe o no, y cuáles son los rasgos que la hacen única a los ojos de sus miembros (vertiente concreta); pero se da por sentado que los Estado-nación existen como un hecho 'natural', como 'contenedores de poder' acotados por fronteras dentro del complejo universal del 'concierto de las naciones' (vertiente abstracta).

La doctrina nacionalista de los Estados no tiene nombre y en consecuencia no puede percibirse como problema. En general. se convierte en una ideología invisible reflejada en un gran complejo de creencias, asunciones. hábitos. representaciones y prácticas profundamente irratgadas pero no percibidas, que se reproducen de modo 'banal: y sólo se explicita en ocasiones especiales, cuando lo 'evidente' se ve puesto en causa desde el exterior o amenazado en el interior por algún emergente nacionalismo sin Estado. 
Michael Billig nos previene sobre la tentación de confundir banalidad con indefensión. El nacionalismo banal no es inocente, ni mucho menos; simplemente goza de su situación de tranquilo predominio, pero está siempre dispuesto a mostrar sus poderosas garras a la mínima contestación. Uno de los muchos resortes ideológicos puestos en marcha para preservar su banalidad es la pirueta de reducir el campo semántico del 'nacionalismo' a los movimientos generados en base a las naciones sin Estado; de ese modo, 'nacionalismo' se identifica con 'problemas' y se relega al espacio de los fenómenos periféricos. Y lo curioso es que esos nacionalismos sin Estado se ven condenados a reforzar con su conducta tal punto de vista. Así los llamados nacionalismos étnicos, privados de un puesto reconocido en el 'concierto de las naciones' al que creen tener derecho, esgrimen su ideología de forma agresiva y explícita apoyados en el principio de que toda nacióncomo-pueblo debería convertirse en nación-como-Estado (Billig 1995:24).

Pero lo que ahora interesa a nuestro objetivo no son los mecanismos de lucha para mantenerse $o$ acceder al concierto de las naciones. Lo que conviene resaltar es la vigencia universal de la ideología subyacente, el hecho de que está asumida e interiorizada -hasta hace muy poco sin fisuras- por tirios y troyanos. Según la ciencia política, un Estado se caracteriza por su capacidad de ordenar la vida de la gente dentro de su territorio, poseyendo como instrumento coercitivo el monopolio del uso legítimo de la fuerza. Traducido a la ideología del Estado-nación, eso se transforma en la existencia de una soberanía, una cultura específica, unas fronteras y una lengua propia. Y esto nos parece tan natural que rara vez nos percatamos de la construcción social que está detrás de esas formulaciones. Incluso hoy día, cuando ya presenta evidentes síntomas de debilitamiento, los efectos de tan extendida concienciación determina unos hábitos de pensamiento que oscurecen nuestro campo de estudio.

Desde nuestra perspectiva, los nacionalismos periféricos atentan contra el actual concierto de naciones, pero en abstracto apoyan sus principios. En ese sentido no son tan peligrosos para la ideología del Estado-nación como el proceso de globalización. Este sí que es una amenaza directa, porque debido a su desarrollo la rejilla jurídico-política formada por los Estados deja escapar cada vez en mayor medida lo más sustantivo de lo que sucede hoy en el mundo. Y esto es atribuible a la emersión de un espacio sin límites ni fronteras, inmediata y permanentemente accesible a la comunicación y por ende al intercambio económico y sociocultural. En tal espacio rige la ley de la selva y los Estados apenas pueden hacer algo. Si de algún modo puede definirse en sus aspectos simbólicos un fenómeno tan evasivo y pervasivo a la vez es diciendo con Gonev (1997:410) que consiste en tomar un solo mundo como principal referente explicativo de los procesos sociales. Otra cuestión que excede el ámbito de este trabajo es si identificamos ese 'solo mundo' con la sociedad-red de Castells (1998) o con su máximo impulsor y beneficiario -el Primer Mundo con Estados Unidos a la cabeza.

El antiguo 'orden mundial' presidido por el concierto de las naciones está haciendo aguas por la vía de los hechos; como de costumbre, la dinámica social se ha adelantado al pensamiento de los analistas. Estos han estado encandilados durante décadas por la idea de la Aldea Global. esa imaginativa premonición de McLuhan que sólo muy parcialmente se ha plasmado en la realidad. Sencillamente, sucede que la prevista homogeneización cultural universal no es necesaria para el funcionamiento del Gran Mercado.

Como bien señala Vidal Beneyto (1997), detrás de todo esto está la intención compartida por muchos implícitamente de dotar de efectividad al mercado mundial; y esto exige eliminar los obstáculos y limitaciones que representan las legislaciones nacionales. Lo que se busca y se obtiene con la globalización no es que todos acabemos cortados por el mismo patrón, sino la 
creación de un espacio a-legal en el que se circula según pautas que ese mismo espacio se autoconfiere, sin imposiciones de los llamados poderes soberanos. Los protagonistas de tal dinámica -empresas multi y transnacionales. iglesias. ONGs. mafias, redes de científicos o artistas afines...defienden unánimemente y con todas sus fuerzas su autonomía y endogeneidad: todos coinciden en el rechazo a cualquier tentativa de someterlos a leyes comunes.

Queda por consiguiente claro que fragmentación de la sociedad y globalización no son dos fenómenos antagónicos sino complementarios. Parafraseando a Vidal Beneyto, constituyen los dos polos antónimos de una paradójica simbiosis que caracteriza la realidad mundial del momento. De ella están siendo desplazados los Estados: y no tanto porque se los hayan comido por arriba y por debajo otros agregados territoriales cuanto por el deterioro de su poder de organizar la vida social mediante normas de obligado cumplimiento.

Con todos sus defectos, el sistema del 'concierto de las naciones' tenía al menos la virtud de amparar hasta ciertos límites los derechos humanos y la igualdad ante la ley. Pero el mundo que nos ha tocado vivir está experimentando un rápido proceso de desregulación porque se han aflojado las riendas de los Estados sin ser sustituidas por un orden jurídico global que restituya al menos formalmente- la ética de la responsabilidad y la solidaridad.

En síntesis, la globalización está ampliando nuestra capacidad productiva y nuestra creatividad cultural, al tiempo que está privando de sus derechos humanos a las sociedades (Castells, 1998:91). En paralelo, los Estados están perdiendo protagonismo y capacidad para controlar el destino de sus ciudadanos, mientras que paradójicamente los nacionalismos incrementan su vigencia. Esto último incluye también al 'nacionalismo de Estado' que, inquietado en su banal hegemonía, adopta cada vez más las actitudes agresivo-defensivas que antes le reprochaba a los 'nacionalismos periféricos': por toda Europa está subiendo la inquietante marea negra del chauvinismo y la xenofobia.

\section{2. La heterogeneidad legitimada}

El universalismo homogenístico ha sido la epistemología dominante durante siglos en el ámbito intelectual de Occidente, salvo ocasionales rebeliones tales como el nominalismo medieval, el existencialismo o la más reciente tendencia postmodernista. Entre el común de los humanos refiriéndonos siempre a la esfera occidental- se reconocía la heterogeneidad entre comunidades, pero no en su seno y menos en el de los grupos. Aquí debe reconocerse de nuevo la omnipresente influencia de la ideología nacionalista, que prescribe para cada nación-Estado una lengua y una cultura no sólo únicas sino uniformes.

El problema de estos planteamientos es que la heterogeneidad a todos los niveles es una constante en el seno de la humanidad. Algunos valientes se atrevieron a proclamarla, pero desde Heráclito hasta hace poco sus voces fueron acalladas por la ficción dominante.

Hoy día las cosas son distintas. Desde el florecimiento del postmodernismo (por lo menos) se ven con ojos tolerantes los estudios sobre la identidad y la diferencia; incluso se admite sin problemas que hay una tendencia humana a crear distinciones donde no las hay o a magnificar las escasas que puedan detectarse. Una prueba de que el ambiente social ha cambiado es que a nadie se le ha ocurrido quemar en la hoguera (simbólicamente, por supuesto) a un Maruyama que defiende (1995) la inevitable existencia de 'paisajes mentales' -esto es, estructuras epistemológicas 
populares- radicalmente distintos entre sí en los miembros de uni misma comunidad: ni tampoco a los cibernéticos que pregonan la heterogeneidad como rasgo necesario fara la supervivencia de los sistemas complejos.

Cabría decir que la modificación del juicio social sobre este punto ha ido de la mano -mediante un circuito mutuamente causal- de los cambios revolucionarios acaecidos en la estratificación social: astillamiento de las élites, consolidación de 'subclases' descolgadas del establishment y ampliación y diversificación desmesurada de la clase media. La percepción de tales cambios acarrea el correlativo reconocimiento de una fuerte heterogeneidad que no es explicable sólo en función de fronteras de clase.

El nuevo factor explicativo de la heterogeneidad es la creciente tendencia al individualismo, a la 'realización personal'. Tanta importancia se le atribuye a este impulso que Touraine (1990) lo considera uno de los dos grandes componentes del concepto de modernidad. Obsérvese además que una consecuencia lógica de este nuevo enfoque es el abandono del concepto monolítico de cultura. Así lo hace por ejemplo Giddens en una obra reciente (1991); pero los toques de atención son anteriores incluso al desarrollo pleno de las teorías de la modernidad. Por ejemplo, en la década de los treinta subrayaba ya George Mead las posibilidades que ofrecía la vida en las sociedades occidentales para escapar de las limitaciones de un único y claustrofóbico mundo social. Y poco después Karl Mannheim basó su aparato conceptual en la coexistencia, dentro de una misma sociedad, de 'ideología' y 'utopías' productoras de imágenes disímiles de la realidad social.

Más tarde, los paradigmas microsociológicos toman el relevo. El énfasis que pone el enfoque interactivo sobre los símbolos y la comunicación es condicionante para el desarrollo de la idea de complejidad cultural. En definitiva, la fuerza de los hechos obliga a entender la cultura, más que como un conjunto unitario armónico, como una especie de 'repertorio cultural' donde cohabitan diversas y hasta contradictorias visiones del mundo y de la forma en que imaginan insertarse en él los miembros de una sociedad. Lo que da coherencia al conjunto es un elemento relacional hasta ahora descuidado pero de trascendental importancia, que impone un orden 'ecológico' en la aparente jungla.

He aquí una perspectiva fructífera. No es descabellado concebir una cultura -aplicando analógicamente los planteamientos de Vickers (1968) sobre las estructuras mentales- como un ecosistema, donde las distintas concepciones y modos de sentir y evaluar se esparcen y colonizan el ámbito societario, chocan, se excitan, modifican y destruyen unos a otros o preservan su identidad por medio de extrañas acomodaciones con sus rivales.

De ese modo se adelanta mucho camino en la comprensión de la actual heterogeneidad cultural. Pero todavía conviene dar un paso más para superar la arraigada presuposición de que la existencia de estilos de vida disímiles, ya reconocida ampliamente en la década de los sesenta, se explicaba en función de las clases sociales. Y ello era así tanto por influencia de las escuelas sociológicas inspiradas en la doctrina marxista como por el enorme predicamento de la obra de Bourdieu 'La distinction' (1979).

La investigación empírica demuestra, sin embargo, que la existencia de distintas formas de vivir y ver la vida no puede atribuirse exclusivamente a ninguna de las categorías clásicas de edad, sexo, nivel de instrucción o clases sociales, porque no coinciden con ellas unívocamente. Es cierí que determinados rasgos sociodemográficos están significativamente relacionados con 
los sistemas de valores distintivos de cada una de esas formas de vivir, con sus correspondientes actitudes y opiniones suore áreas relevantes de la vida e incluso con los hábitos de conducta asociados a ellas. Pero en cada caso se trata de un cierto conjunto de rasgos sociodemográficos; esto es, no todos y no siempre los mismos.

Asi pues, los hechos apuntan a que el sistema cultural de las sociedades modernas aparece diversificado en varias pautas dotadas de una cierta congruencia interna, cada una de las cuales caracteriza a un específico segmento de la sociedad. Aunque la confusión conceptual y terminológica es considerable, hay un cierto consenso en denominar estilos de vida a esas maneras diferenciales de vivir y -con menor grado de consenso-sociotipos a los respectivos segmentos sociales que se asocian a aquéllos.

El factor más explicativo de la nueva heterogeneidad es la creciente tendencia a la realización personal, que cada vez se considera un fin más legítimo. Sobre todo después del impacto producido por el llamado postmodernismo, que Giddens prefiere denominar modernidad aranzada. Este autor (1991) atribuye el fenómeno a que el acontecer social se ha liberado -al menos en parte- de las fijaciones de tradición y costumbre. En virtud de ello aparecen simultáneamente dos factores en las vidas de las personas: una 'política emancipatoria', basada en la ética de los derechos humanos. dirigida a aliviar a la gente de las presiones de la explotación. la opresión o la desigualdad social; y una 'política de vida' que considera legítima la creación de unas formas de vivir que promuevan la autorealización en el contexto de la interdependencia global. Esas dos políticas se interfieren y excitan mutuamente para crear una variedad de nuevas opciones (o estilos de vida), guiadas sólo por una 'moralidad de autenticidad'. El resultado, según Giddens, es la coexistencia relativamente pacífica de múltiples universos simbólicos, diferenciados entre sí pero hasta cierto punto abiertos y vulnerables a las cambiantes definiciones que 'los otros' emiten. He aquí un nuevo factor de la máxima importancia: el hecho de que un estilo de vida no es una torre de marfil, sino que depende en buena medida de su forma de cohabitar con los otros.

Ante la evidencia de la coexistencia de variados estilos de vida, algunos autores sostienen, con cierta razón, que hay más variación cultural en el interior de los países que entre, ellos, dado que los estilos de vida parecen trascender las fronteras entre los Estados del 'Primer Mundo' y aparecen con ligeras modificaciones en casi todos. Desde esta perspectiva, la homogeneización creciente del ámbito europeo, demostrada en numerosas investigaciones, no se debe tanto al avance de la 'aldea global' de McLuhan -que produciría una completa igualación cultural- como al hecho de que los países de Europa son cada vez más parecidos en las formas de su heterogeneidad interna. Como se acaba de apuntar, y dejando aparte la aparición esporádica de algún estilo de vida particular y privativo, en todo el Occidente suele hallarse un abanico similar de estilos de vida, aunque varíe el peso específico de cada uno en cada país.

Hay un extendido consenso sobre el protagonismo individual en la creación del 'estilo de vida' de cada persona. En su base hay casi siempre elecciones personales, más o menos conscientes, más o menos forzadas o constreñidas por las circunstancias. El proceso ha sido muy bien retratado por el profesor Juan (1993): la adscripción de una persona a un 'estilo de vida' determinado es la consecuencia de una síntesis entre las condiciones externas dadas y las estrategias subjetivas de vida puestas a punto por el individuo a tenor de sus orientaciones personales.

Por otra parte. está empíricamente contrastado que esas síntesis personales no se producen estocásticamente; el producto final no es una distribución plana ni en forma de curva normal, sino llena de concentraciones y rarificaciones Sin esa formación de conjuntos relativamente 
homogéneos no existirían los 'estilos de vida' como fenómeno social; porque lo característico es. precisamente, la existencia de 'sociotipos', de segmentos sociales que profesan una manera diferencial de vivir.

Según esto. los 'estilos de vida' son un fenómeno complejo y colectivo en cuya raíz cabe identificar impulsos individuales y constricciones sociales y culturales en interacción. Resulta curioso constatar que la heterogeneidad cultural moderna asentada en los 'estilos de vida' erige unas identidades donde está difuminado el 'otro' que debería servir de contraste. La distinción se hace primordialmente frente al 'común', del que el sujeto y sus semejantes se sienten distintos, aunque algunos más distintos que otros. Usando términos más técnicos, resulta que los 'sociotipos son conjuntos borrosos, cuyos difuminados límites no impiden la constitución de identidades más bien de corte individual- pero apenas dan pie para fenómenos de exclusión.

Probablemente el mayor obstáculo práctico para ello es la débil identificabilidad de los miembros de los 'sociotipos' porque en general ( $y$ a la inversa de lo que sucede con las clases sociales) no existen en el campo de los 'estilos de vida' unos signos visibles a primera vista tan poco ambiguos como los símbolos externos de status que, mal que bien, suscitan expectativas pautadas en base a la estratificación social.

Los 'sociotipos', en suma, tienen un claro déficit en marcas de identidad directamente accesibles. Salvo excepciones, ofrecen poca carnaza para el juego de las clasificaciones y los etiquetajes automáticos. De cualquier modo, los 'estilos de vida' constituyen la expresión más característica de la heterogeneidad en la modernidad avanzada. Pero son identidad difícilmente identificable; y no generan mucho potencial de exclusión aunque sí forman parte del caldo de cultivo - a través de la afinidad y la empatía- para el agrupamiento en conjuntos y grupos más estructurados.

\section{3. Heterogeneidad y globalización}

La legitimación social de la heterogeneidad, sin embargo, no explica por sí misma la enorme proliferación de nuevas identidades de que hace gala nuestro mundo. Y es que junto al ya descrito protagonismo de la realización personal -que puede considerarse una fuerza endógena de la modernidad - actúan también los efectos de la globalización.

Entre ellos destaca la erosión del Estado del bienestar, recortado progresivamente por la creciente pérdida de ingresos de las Haciendas públicas (Martin \& Schuman, 19\%). Hacia 1995 el flujo financiero internacional -incontrolable por los Estados-era ya setenta veces superior al comercial; entre otras cosas porque los beneficios empresariales generados en cualquier lugar se residencian en las plazas donde menor es la fiscalidad. A esto se añade que la creciente productividad derivada de los avances tecnológicos determina una menor cantidad de horas de trabajo por unidad de producto.

Esta reducción en la necesidad de mano de obra se había venido compensando históricamente con un paulatino acortamiento de la jornada laboral. Sin embargo, ese proceso equilibrante se cortó a raíz de la segunda guerra mundial; el 'ejército de reserva' de trabajadores potenciales ha venido incrementándose desde entonces, con el agravante de la incorporación masiva de la mujer al mercado laboral. Si a esto añadimos la penuria de recursos de los Estados para impulsar políticas efectivas de empleo o, alternativamente, para establecer un sistema digno 
de subsidios, nos encontraremos con una creciente tasa de parados, muchos de los cuales carecen de cobertura social.

Así aparece otra línea de ruptura característica de las sociedades avanzadas. Cada vez es más usual que un europeo no llegue a tener en toda su vida un empleo 'verdadero'. En base a estas premisas, Parijs (1993:224) profetiza que bajo ciertas condiciones surgirá una nueva lucha de slases entre los 'instalados' -sean empleadores o empleados- y los 'pobres de empleo'. Tal lucha plede que no se declare (aunque así lo auguran recientes asonadas en Inglaterra. Francia y en menor medida España). pero no cabe duda de que la globalización ha introducido unas nuevas categorías en el ámbito económico que. por su trascendencia. son potenciales creadoras de identidades básicas.

Sin ánimo de agotar el tema. conviene también reseñar otro significativo efecto de la gobalización en nuestras vidas. Los estímulos que introduce en todos los ámbitos agitan las bases cognitivas de la orientación y la acción (Gonev, 1997:416). Desaparece la certeza de sstructuras bien estratificadas y de visiones del mundo unificadoras. La alta intensidad de riesgo. unida a la inhabilidad institucional para gestionarlo conduce a actitudes defensivas. Las estrategias personales se encaminan a una cierta rebaja en sus aspiraciones, a un acortamiento de los plazos en cualquier planificación y en el abandono de principios altruistas y universalistas. Cuando uno ha de ajustarse a los nuevos entornos se pierden partes del 'yo social'. Esto genera una impresinnante reacción en forma de búsqueda intensiva de lazos emocionales y neo-institucionales (ibid.:418) fundados en una idea concéntrica de la solidaridad: yo contra mi hermano, mi hermano y yo contra el clan. el clan contra el mundo. De ahí a la adopción de identidades colectivas defensivas y excluyentes no hay más que un corto paso.

\section{DIALÉCTICAS DE IDENTIDAD Y EXCLUSIÓN}

Globalización y heterogeneidad. unidas como hemos visto en una simbiosis donde cada elemento realimenta al otro, están también ligadas al incremento de la información disponible. Esa tríada de factores impulsa a su vez a los humanos a desarrollar sistemas de clasificación social crecientemente sofisticados que les sirvan para orientarse. autodefinirse a tenor de las circunstancias y actuar en una situación lábil llena de riesgos incontrolables. Y tales autodefiniciones, individuales y colectivas. generan los correspondientes 'otros' más o menos excluidos de un círculo de solidaridad que tiende a ser tribal en perjuicio del universalismo y de la justicia social. Este conjunto de fenómenos está ligado por relaciones que se denominarían dialécticas a tenor de la terminología clásica y que hoy, con el desarrollo de la sociocibernética, empiezan a llamarse 'relaciones sistémicas': modos de influencia mutua donde los circuitos de realimentación así como las reacciones mutuas entre cada elemento y su entorno crean una dinámica de producción de cualidades emergentes.

Pero veamos con cierto detenimiento algunos de los detalles de la referida dinámica.

\section{1. Incremento de la información}

Es claro que los procesos globalizadores no podrían tener lugar sin una eficaz red de comunicaciones. donde la información privilegiada tiene un papel de primer orden. Forman parte de este flujo los lugares idóneos para colocar los centros de control. de producción y de domicialización fiscal: los procedimientos exitosos de ingeniería financiera; los argumentos más eficaces que esgrimir ante las instituciones locales. 
Pero el aumento de la información no pertenece sólo al campo de la economía. Todo poder emergente ha de contar con su aparato de propaganda y persuasión, con un conjunto de valores que inculcar, entre los que destacan la eficiencia tecnológica (Gonev, 1997:423) y el consumismo (cf. Parsons, 1971). Es precisamente la buena organización de ciertas empresas de servicios lo que ha impulsado a una amplia uniformidad en el consumo de determinados productos -de espectáculos, de comida rápida o de bebidas, por ejemplo-. En lo relativo a otras pautas, el pretendido imperialismo cultural americano es más aparente que real debido a tres factores: uno, que el valor más generalizado ha sido el de la autorealización y autenticidad personal; otro, que los procesos reactivos están ganando la partida a los homogeneizadores; el tercero, que la polarización Norte/Sur se va profundizando.

El resultado puede resumirse en el título de la obra de Barber (1996) Guerra Santa versus McWorld: Cómo la Globalización ye el Tribalismo están reconfigurando el Mundo. El trabajo conjunto de los medios de comunicación y de las migraciones masivas sobre el imaginario colectivo produce un enorme grado de inestabilidad en la creación del yo y de las identidades (Appadurai, 1996:4).

Según la teoría de Shannon, la información transmitida se hace máxima en los puntos críticos (cf. Solé et al. 1996); quizá la afirmación sea reversible y una gran cantidad de información genere las condiciones para acercarse e incluso llegar a 'transiciones de fase' con la consiguiente imposibilidad de predecir el futuro. Al fin y al cabo, los sistemas complejos -y los sociales lo son por excelencia- evolucionan bajo el principio de 'criticalidad autoorganizada' formulado por Per Bak en 1988: los sistemas son atraídos hacia un punto crítico; una vez alcanzado éste, la tendencia a una mejor adaptación por parte de los elementos genera inestabilidades que se propagan a todas las escalas, generando correlaciones (propiedades emergentes) que abarcan al sistema entero. En síntesis, la sociedad actual vive al filo del caos, a medio camino entre orden y desorden.

En ese contexto, la abundancia de información conduce a muchos fenómenos interesantes para el sociólogo comprometido o simplemente curioso. Por ejemplo, la necesidad de reforzar por un lado las habilidades en la búsqueda de la información que cada uno considere relevante y, por otro y correlativamente. los mecanismos de acorazamiento contra la información no deseada. Esto último, dicho sea de paso. conduce a una especie de exclusión cognoscitiva que impide contrastar y enriquecer nuestras imágenes estereotipadas sobre los 'otros', contribuyendo así a la persistencia de las exclusiones sociales.

Finalmente, y sin pretensiones de exhaustividad, la variedad de información a nuestro alcance ofrece la posibilidad de desarrollar aspectos muy disjuntos de la línea principal de nuestras actividades. Y eso conlleva invasiones indeseadas en el terreno de otros, bien en el campo cognoscitivo bien en el de las identidades colectivas. Si consideramos el primero de los ámbitos citados, la consecuencia es que muchos aficionados cualificados por la vía autodidacta invadan 'impúdicamente' el territorio de quienes están acreditados como expertos o profesionales en la materia; éstos, ofendidos por la intrusión, se apresuran a levantar barreras de exclusividad en sus pequeñas parcelas, operacionalizan métodos de descalificación muy estrictos $y$, en definitiva, acaban dividiendo las áreas del saber -privándose de los beneficios de la interdisciplinariedad y de las posibles ideas refrescantes de los intrusos- en un rompecabezas de piezas radicalmente incomunicadas.

Una dinámica similar se desencadena en el campo de las divisiones sociales. Los curiosos, los investigadores o los simplemente bienintencionados que se acercan a un colectivo corren el 
Hesgo de ser rechazados sin más porque 'nadie que no sea de los nuestros puede entendernos'. La nuda social a los grupos marginados se dificulta extremadamente, la comunicación querida verpetúa los malos entendidos y las exclusiones mutuas se refuerzan. Por la parte que nos toca, el nroblema es más triste cuando vemos proliferar los científicos sociales 'nativos' que, encarnando el peor de los males del antisociólogo -tal y como lo definió Merton (1975)-. descalifican a sus - olegas foráneos con el argumento de que 'los que no sean de aquí son incapaces de captar los más importantes matices de nuestra forma de ser'. Olvidan, sin duda, que precisamente lo más común es que sin una perspectiva de lejanía los árboles no dejan ver el bosque.

En síntesis, los procesos desencadenados por la superabundancia de información contribuyen, por diversos caminos, a añadir más complejidad a los ya de por sí complejos temas viales de orientación ante los 'otros' en un mundo donde las identidades individuales y colectivas no sólo son superabundantes y están regidas por dispares criterios de clasificación, sino que .demás cambian a ritmo vertiginoso.

\section{2. De clasificaciones y etiquetajes}

Si los humanos somos 'animales clasificadores' es porque la clasificación es el instrumento primordial que empleamos para orientarnos en nuestro entorno. Clasificar equivale construir el ventido de los entes, los fenómenos, las situaciones y los procesos que se presentan ante nosotros, atendiendo a un conjunto trabado de atributos culturalmente asumidos.

Desde la perspectiva científica. llena de orden y de razón, tendemos a concebir las clasificaciones -y no sólo las nuestras- desde la perspectiva de la lógica de clases, que está fundamentada en principios rígidos de inclusión/exclusión; y cuando hay varias clasificaciones en cadena las jerarquizamos también rígidamente. El problema es que los fenómenos sociales presentan una complejidad extrema, resuelta por los seres humanos mediante su reducción a un número finito de categorías. Cuando los fenómenos no admiten ser sometidos a una lógica de clases -lo que Eriksen (1993) denomina una clasificación digital, típica de nuestra tradición escolástica-, se acude a las clasificaciones analógicas, basadas en las diferencias de grado.

Este tipo de operación, que a algunos podría parecer anticientífica, no sólo es practicada habitualmente por la 'teoría popular'; también tiene una respetabilísima trayectoria intelectual cuyos primeros tratamientos escritos datan del siglo $\mathrm{V}$ a.C. y desembocan hoy día en la 'lógica borrosa' formalizada por Zadeh (1987) durante la década de los setenta en el Instituto de Tecnología de Massachussetts. Muy diferente al 'pensamiento débil' puesto de moda por el postmodernismo, este tipo de lógica permite contemplar el campo de las variedades como sujeto a una clasificación dendrítica difusa, donde los fenómenos más concretos se funden progresivamente para configurar unidades más abstractas sin sujetarse al sacrosanto principio del tercio excluso.

Luego vienen otros mecanismos para fijar y delimitar mejor esas clasificaciones confusas. Por ejemplo, en el campo de las identidades sociales y sobre todo las de tipo territorial. Las identidades colectivas con base geográfica presuponen una 'teoría popular' de la comunidad, que imagine el territorio dividido en tales comunidades que, a su vez, han de ser imaginadas en zuanto tales. No están construidas alrededor de criterios objetivos claros excepto, en su caso, por la existencia de demarcaciones político-administrativas que rara vez coinciden exactamente con a área considerada como tierra-madre. No son. pues. comunidades 'objetivas' en sentido estricto han de ser imaginadas (Anderson. 1983) por un proceso de doble categorización: primero, las 
personas han de catalogarse a si mismas como pertenecientes a la comunidad; y simultáneamente han de imaginar la colectividad a la que deciden pertenecer.

De ese modo surgen y se mantienen las etnicidades que, como dice Eriksen (1993), conforman un aspecto de las relaciones sociales entre las personas que se autoconsideran culturalmente distintos de los miembros de otros grupos con los que tienen un mínimo de interacción regular. Sólo cuando las diferencias culturales se perciben como algo socialmente relevante se da un elemento étnico. La etnia, en este sentido, es una creación ideológica ligada a procesos históricos; pero una vez surgida la identidad colectiva, esa historia se reescribe como un reflejo de los equilibrios y luchas del presente (Billig, 1995). Cada comunidad se convierte en interpretadora de su pasado para subrayar los estereotipos de carácter y temperamento que revelan el carácter único de una cultura concebida como una herencia genética preciosa (Balibar \& Wallerstein, 1991). Imaginar que la comunidad tiene una identidad clara y documentada es condición para poder esgrimir con fuerza una identidad colectiva.

En definitiva. el mundo social está organizado por una compleja red de distinciones entrecruzadas -en parte intersectantes, en parte jerarquizadas- y no necesariamente concongruentes (Pohoryles \& Crowley, 1998). Esas distinciones integran esquemas clasificatorios, lo cual implica establecer límites más o menos borrosos que otorgan sentido al mundo. El conjunto de estas fronteras diseña y valida (salvo que se produzca contestación) un mapa cognitivo en cuyos términos -como un pez que se muerde la cola- se justifican las distinciones.

Es de advertir que todas las clasificaciones, cuando se las despoja de sus ficciones concomitantes, son borrosas a la postre. Requieren pues ser 'digitalizadas' en el sentido dado por Eriksen (es decir, vertidas a una lógica de clases), pero siempre quedan casos de imposible encaje por su carácter radicalmente fronterizo. Mientras más se refugia un actor social en esquemas sencillos, más crece el número de casos problemáticos que exigen un detenido examen discriminante para decidir en qué clasificación encajarlos o en qué lado de la clasificación 'oportuna' caen.

Nadie tiene, y menos en el mundo actual con su superabundancia de estímulos, un sistema clasificatorio neto y totalmente jerarquizado. En un plano abstracto cualquier fenómeno social es susceptible de clasificación según múltiples posibilidades. De hecho, y parafraseando a Garfinkel (1967), la operación de dar sentido a algo por vía de clasificación supone: primero, decidir mediante unas 'reglas básicas' cuál es el modelo clasificatorio aplicable al caso; y segundo, encajar el caso en una de las alternativas del modelo seleccionado. Aquí las 'reglas básicas' están constituidas por ciertos rasgos estratégicos de la situación que funcionan a modo de conmutadores para navegar por el sistema clasificatorio y que forman parte inseparable del mismo. En términos clásicos de la etnometodología, sirven para 'indexar' las clasificaciones.

No es fácil para la mente humana retener en la parte más accesible de la memoria todo el caudal de información que supone colorear con abundantes detalles y matices cada ítem de esa selva clasificatoria. Lo habitual es, por tanto, simplificar al máximo la caracterización de la mayor cantidad posible de alternativas mediante la clásica operación de etiquetaje. Especialmente en los ítems que nos parecen más lejanos, más extraños o más reprobables, tendemos a identificar la correspondiente categoría con una etiqueta; entonces se vacía de contenido la categoría etiquetada, que sólo contiene a partir de ese momento algún simple estereotipo y el correspondiente prejuicio, ambos asociados ya indisolublemente a la etiqueta. Este mecanismo de sustitución. tan comúnmente practicado, es el que está en la base de los procesos de exclusión más profundos y duraderos. 


\section{3. Identidades y exclusiones}

Es obvio que cuando una clasificación incluye en alguna de sus categorías al yo, forma parte de los caminos para establecer la identidad. Pese a que comúnmente se considera que el conocimiento de uno mismo es un descubrimiento, en realidad es siempre una construcción (Calhoun, 1994:9). Más exactamente. una construcción de sentido a la que se da prioridad sobre el resto de las fuentes (Castells. 1998:28).

También es obviamente erróneo decir que alguien tiene una sola identidad. Pese a su prurito de exclusividad, las identidades sociales son de carácter segmentario (Evans - Pritchard, 1940) y pueden ordenarse parcialmente como círculos concéntricos. Son múltiples y se entrecruzan, de forma que cada individuo tiene una identidad compartida con personas diferentes en momentos diferentes. Uno puede sentirse antequerano, malagueño, andaluz, español o europeo según defina a los 'extraños' en cada situación. Estando las autocategorizaciones asociadas a una determinada clasificación, les son de aplicación las reglas que rigen para estas últimas: funcionan a modo de interruptores-conmutadores que encienden o apagan aspectos de la identidad social para emplearlas como la identided en situaciones relevantes (Hutnik. 1991). Esto, por supuesto, no desmiente la existencia de lo que Castells (1998:31) denomina 'identidad primaria', que tiende a enmarcar al resto y se sostiene por sí misma a lo largo del tiempo y del espacio.

Visto el asunto desde otro ángulo, es evidente que para la configuración de la identidad propia son necesarios los 'otros'; aunque siempre hay una amplia variedad de 'otros', clasificados según su relevancia dentro de nuestro mapa simbólico (Billig. 1995). Son 'otros' indexados, de modo que el contexto de la situación realza la relevancia de cada uno en cada momento, destacándolo dentro de nuestro mapa simbólico de grupos de referencia el cual -cuando se trata de identidades colectivas- está reforzado por un conjunto de creencias más o menos compartidas por quienes nos acompañan en la formación del 'nosotros'. En una palabra, tras cada identidad colectiva subyace una creencia emic -lo que antes se ha denominado 'teoría popular' que marca sus límites a la vez que le sirve de justificación ideológica.

Muchas de nuestras identidades sirven. formal o informalmente, para gestionar una amplia sariedad de recursos; para economizar, en otras palabras. los costes de información requeridos para discriminar la atribución de los recursos a nuestro alcance (Pohoryles \& Crowley, 1998). En síntesis, el sentimiento de pertenencia es lo que nos permite la administración de solidaridad. Pero describir esos procesos sólo en términos de sus funciones 'económicas' es despreciar mucho de su significatividad. El mejor modo de enfocar los fenómenos de identidad/exclusión es centrarse en la articulación entre: las teorías emic en cuya virtud se llenan de significado las fronteras trazadas; los procesos por los que dichas fronteras se diseñan y mantienen; y las consecuencias tanto inmateriales como tangibles de esa identidad/exclusión.

El máximo problema que presentan bastantes de las identidades de la modernidad avanzada es que tienen carácter defensivo. Los sujetos (personas o colectividades). cuando se construyen o reconstruyen ya no lo hacen basándose en las sociedades civiles que. al ser 'aparatos' prolongadores -Gramsci dixit- de la dinámica del Estado entre la gente. están en proceso de decadencia; sino como una prolongación de la vida comunal (Castells. 1998:34). El impulso a la resistencia a la globalización homogeneizante (o el sentimiento de estimarse en posiciones devaluadas 0 estigmatizadas) genera un 'sentido de comuna' que al reforzar su frontera parroquial. puede acabar en la exclusión de los exclusores por los excluidos (ibid.:32). 
Y los procesos excluyentes conllevan una alta probabilidad de que se desencadene la conocida dinámica de la profecía que se cumple a sí misma: la dinámica social hace que los excluidos tiendan a acercarse a los estereotipos que se les adscriben, justificando así cada vez más los prejuicios asociados a su etiquetaje. Una exacerbación de tal tendencia llevaría a un futuro con claro predominio del modelo tribal de solidaridad y a una escandalosa disparidad en la atribución de recursos de cualquier tipo (incluidos los emocionales). Y a ello quizá haya contribuido la caída del socialismo real, que al fin y a la postre tenía el prurito de estimular una solidaridad universalista representada simbólicamente por el apelativo de 'camarada'; aunque ese prurito, al ser llevado más allá de lo que consiente la naturaleza humana, produjo constantemente rechazos muy generalizados.

La cuestión es que el ser humano requiere un equilibrio entre ambos modelos de solidaridad. Por una parte, no soporta el imperio exclusivo del universalismo ni el peligro real o imaginado del 'ninguneo' derivado de la globalización masificante; por otra, el avance general del principio de los derechos humanos hace impensable negar el pan y la sal a cuantos estén fuera del 'nosotros' comunal.

De ahí que quepa esperar tanto nuevas aperturas a la tolerancia como duras cerrazones autodefensivas (Gonev, 1997). Quizá lo más duro sea que el mundo que nos ha tocado vivir no nos da casi oportunidad para alcanzar un equilibrio personal entre las dos tendencias. Estamos más bien condenados a convivir con una doble personalidad generada por el complejo y confuso circuito de realimentación entre lo local y lo global (Appadurai, 1996:153): la de individuos globalizados por un lado y la de miembros de nuestra tribu por el otro.

\section{BIBLIOGRAFÍA}

Anderson. B.

Appadurai, A.

Bak, P.

Balandier, G.

Balibar, E. \& Wallerstein, L.

Barber, B. R.

Billig, M.

Birch, A. H.

Bourdieu, P.
Imagined Communities. London: Verso, 1983.

Modernity at Large: Cultural Dimensions of Globalization.

Minneapolis: University of Minnesota Press, 1996.

How Nature Works: The Science of Self-Organized Criticality. Oxford: Oxford University Press, 1997.

El Desorden. Barcelona: Gedisa, 1994.

Race, Nation, Class. London: Verso, 1991.

Jihad versus Mcworld: How Globalism and Tribalism are Reshaping the World. New York: Ballantine, 1996.

Banal Nationalism. London: Sage. 1995.

Nationalism and National Integration. London: Lnwin Hyman, 1989.

La Distinction: Critique Sociale du Jugement. Paris: Les Editions de Minuit. 1979. 
Calhoun, C.

Castells, M.

Douglas, M.

Eriksen, T. H.

Evans-Pritchard, E. E.

Garfinkel, $\mathbf{H}$.

Gellner, E.

Giddens, A.

Gimeno, F.

Gonev, N. B.

González Moro, V.

Hutnik, N.

Juan, S.

Mannheim, $\mathrm{K}$.

Martin, H. P, \& Schuman, H.

Jaruyama, M.

JcLuhan, $\mathrm{M}$.

Mead, G. H.

Merton, R. K.

Parijs, Ph. Van

Parsons, T.
Social Theory and the Politics of Identiry. Oxford: Blackwell, 1994.

El Poder de la Identidad. Madrid: Alianza Editorial, 1998.

Purity and Danger. London: Routledge. 1966.

Ethnicity and Nationalism. London: Pluto Press. 1993.

The Nuer. London: Clarendon, 1940.

Studies in Ethnometodology. Englewood Cliffs. N.J. Prentice-Hall, 1967.

Nations and Nationalism. Oxford: Basil Blackwell, 1983.

Modernity and Self-identity. Cambridge: Polity Press. 1991.

Dialectología y Sociolinguística Españolas. Alicante: Universidad de Alicante. $1990\left(2^{\circ}\right.$ ed. $)$.

Four Global Trends: Rise and Limitations. International Sociology. 1997. Vol, 12, No 4.

Cultura. Identidad Colectiva y Estilos de Vida. San Sebastián: Comunicación al III Congreso Español de Sociología, 1989.

Ethnic Minority Identity: A Social Psychological Perspective. London: Oxford University Press. 1991

Estilos. Modos y Géneros de Vida. Bilbao: Ponencia a la Semana de Sociología de Deusto, 1993.

Ideología y Utopía. Madrid: Aguilar, 1958.

Dic Globalisierunsfalle. Reinbek: Row ohlt, 1996.

Individual Epistemological Heterogeneity across Cultures.

Cybernetica. 1995. Vol. 37.

The Gutenberg Galaxy. London: Routledge \& Kegan Paul, 1962.

1914 Class Lectures in Social Psychology. En D. L. Miller (Ed.), 'The Individual and the Social Self'. Chicago: University of Chicago Press, 1982.

Structural Analysis in Sociology. En P. M. Blau (Ed.), 'Approaches to the Study of Social Structurc'. New York: The Free Press, 1975.

Una Rerolución en la Teoría de las Clases. En J. Carabañas \& A. de Francisco (Eds.). 'Teorías Contemporáneas de las Clases Sociales'. Madrid: Editorial Pablo Iglesias. 1993.

The System of Modem Societics. Englewood Clift's N.J.: PrenticeHall. 1971. 
Pérez de Guzmán, T.

Pohoryles, R. J. \& Crowley, J.

Solé, R. V. et al.

Touraine, A.

Vickers, G.

Vidal Beneyto, $\mathrm{J}$.

Weber, M.

Zadeh, L, A.
Reflexivity and Feed-Before: From Sociology to Systemics. Kybernetes. 1997. Vol. 26. $\mathrm{N}^{\circ}$ 6-7.

Introductory Allocution. Preparada para la Special Session of The EAASS. Montréal: XIV World Congress of Sociology, 1998.

Phase Transitions and Complex Systems. Complexity. 1996, Vol. 1.

A Critical View of Modemity. Madrid: Conferencia al XII Congreso Mundial de Sociología, 1990.

Value Systems and Social Process. Harmondsworth: Penguin, 1970.

El Desorden Mundial. Madrid: El País, 1997. 30 de Septiembre, P. 8

El Político y el Científico. Madrid: Alianza Editorial, 1980.

Fuzzy Sets and Applications: Selected Papers. New York: Wiley, 1987. 